\title{
The Conquest of Representation in the Architecture of Guatemala
}

\author{
ANDRZEJ PIOTROWSKI \\ University of Minnesota \\ USA
}

\begin{abstract}
This paper will argue that the connections that exist between architecture and political powers are located in representational functions of architecture. Representation is defined here as a culture-specific process of establishing the relationships between reality and the signs created to symbolize that reality. Architecture of Guatemala provides a unique material to study how representational constitution of symbolic places reflects an ideological struggle of two different cultures. To substantiate this point, I will expand on Tzvetan Todorov's observations made in "The Conquest of America" and show how they could enhance our understanding of the symbolic function of architecture. The discussion of representational attributes and workings of architecture will be informed by a comparative reading of three cities in Guatemala: Mayan ruins in Tikal, colonial city of Antigua, and indigenous Chichicastenango. My objective is to test the workings of this critical inquiry against the geography of power that these three cities represent.
\end{abstract}

\section{INTRODUCTION}

In The Conquest of America, Tzvetan Todorov presents a post-structural reading of documents about this historical event.' His exploration relies mostly on the documents written during that time. Todorov contends that the conquest of America was not only the conquest of a piece of land but also of the world view. The written documents reveal a profound discrepancy in the two concepts of the world and in the means used to understand and to control reality. Consequently, rather than seeing these documents as a direct source of factual information, Todorov studies them to discover their instrumental role in the creation of "historical facts." In his discussion of the Spanish invaders, Todorov shows how letters written by Columbus and Cortés to the King of Spain were used to shape the view of the new world. The letters show a purposeful projection of desires and expectations on what was new and different. No less important was Cortés' use of information in his military strategies. A precise retrieval of information and univocal interpretation to Spanish and back to a native language, were seen as indispensable in conducting the war. Intentional confusion concerning Spanish forces and their objectives, exploitation of local conflicts, and, maybe the most important, the manipulation of traditional beliefs to create military advantage were a common practice in Cortés' warfare. What seems to be especially interesting in this military economy of signs is its double play. The understanding of America fabricated by the conquistadors for their patrons in Spain as well as the understanding of Spain fabricated for their "enemies" in America were primarily grounded in the manipulation of the concept of the self and the other. On the other hand, this intentional deception was constructed and disseminated with unprecedented precision. The Conquest of America describes the finesse of that manipulation of symbolic reality and how it was safeguarded up by the madness of military actions.

Aztec's and Mayan view of the world were very different from that of the Spanish one. This difference is best shown in Todorov's argument that, while the Spaniards were the masters of the interhuman communication, the identity of indigenous cultures relied on their symbolic communication with the world. ${ }^{2}$ The indigenous people's view of themselves was, then, inseparable from the concept of their mythological cosmology. As Todorov asserts, that predictable, even "overdetermined and overinterpreted,"world was deciphered in and through rituals. ${ }^{3}$ Such a ritual discourse, initiated by the memorized interpretations of divinatory signs, was always aimed at constituting or reestablishing universal harmony. And it is exactly this concept and this practice of symbolic reality that made Aztec and Maya people vulnerable to the invaders armed with the modern, that is, operational concept of signification.

In the whole book, there are only a few paragraphs devoted to the symbolic role of graphic depiction. There is no discussion there of how architecture contributed to the struggle of the cultures. Despite Todorov's claim that language was the primary weapon for the war of the two symbolic realities, I wish to assert that architecture took part in this struggle as well. What is more, I wish to suggest that, even nowadays, because architecture reaches beyond the capabilities of historical records, buildings and public urban 
places in Guatemala preserve and explicitly present the nature of this conflict. As a living material and symbolic environment, cities and buildings show contemporary legacy and coexistence of the two concepts of reality. To substantiate my argument, I will explore certain aspects of architecture in the three cities in Guatemala: the ruins of Tikal, colonial Antigua, and indigenous Chichicastenango.

Before I analyze some of architectural aspects of these cities, I would like to discuss a symbolic functioning of Western languages and architecture. Since the "classical era," that is, since the time of the conquest and, especially, since the beginning of the seventeenth century, languages used by the Western nations have been gradually transformed to be, as Michel Foucault calls it, well-formed. They were meant to provide a well-organized system of coding knowledge. Being a code implies that the system itself becomes transparent to the signification it conveys. Thus, language or a scientific notation may be conceived exclusively as a means for rational control, or as a system of operational signs. Ideally, these signs in themselves mean nothing else but the meaning that is intentionally assigned to them. ${ }^{4}$ The ultimate, contemporary, and the most explicit example of such a concept of communication can be found in the constitution of computer languages. These univocal, free from any "metaphoric contamination," codes with their elementary syntactic and semantic structures have a growing impact on the use of languages in general. Since the beginning of these changes in languages, the objective was to develop means for naming and communicating that which would enable analysis and ensure precise transmission of information between a sender and a receiver.

Architecture, as an embodiment of symbolic signs, cannot be reduced to the problem of a transparent code. Decoding any scientific notation differs from interpretation or deciphering sense from thoughts that are triggered and guided by the experiential phenomena of architecture. Rather than communication, representation is the word that better reflects the symbolic functioning of architecture. Representation may be defined here as a culture-specific process of establishing the relationships between reality and the signs created to symbolize that reality. Multiplicity and complexity of these relationships reflect the idea that representation is a process of defining what is thinkable and meaningful in reality. The relationship between a sign constituted in that way and the real becomes, then, the very way a specific culture defines and explores reality. The possible variety of such relationships makes representation vulnerable to the play of political and ideological forces. However, it may be said that the concept of representation preserves the possibility of a dialogue with reality, with the world at large, as an alternative to the communication with an identifiable sender of a massage. As Foucault observes, the shifting symbolic

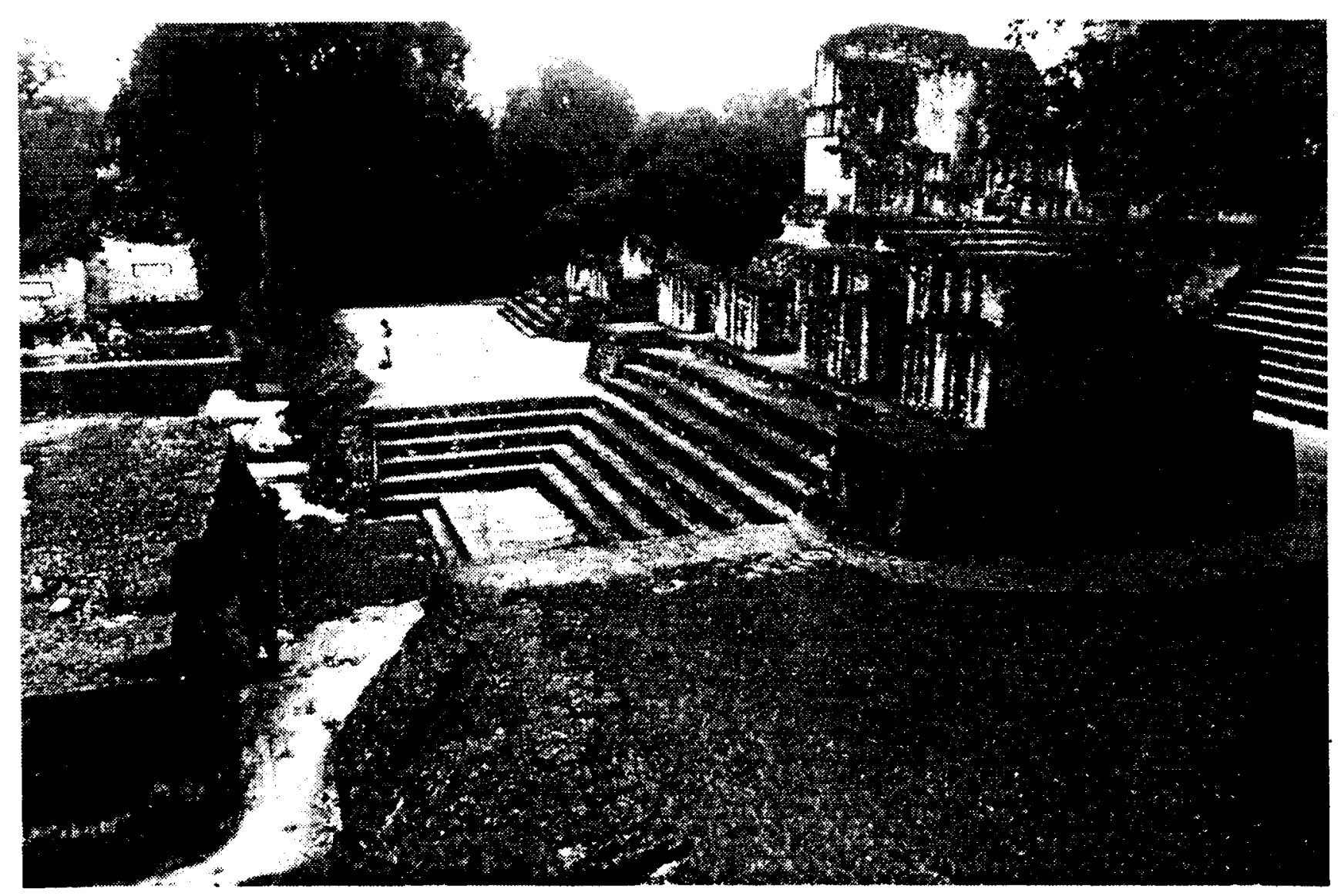

Figure 1. Tikal, North Acropolis 
character of viewing/representing reality not only proceeds but also underlies the principles of knowing and the political/ institutional expression of an episteme. ${ }^{5}$ My analysis of the symbolic functioning of architecture in the three cities of Guatemala will show that the Spaniards intentionally shifted representational attributes of architecture and art to make them a tool of direct communication between the political/ ideological center of their country and the people in America.

\section{TIKAL}

Tikal, the first city I would like to discuss, exists as a material trace of the pre-Columbian era of the Mayan civilization. Despite its obvious symbolic intensity, the representational meaning of that place, its instrumental role in performing rituals or staging political events, remains uncertain for us today. The architecture and its setting have powerful evocative capabilities. Let us try to understand what are the attributes of that city and its architecture that make such an impact on a visitor.

Tikal is a ruin of a large city located in Guatemalan tropical jungle. Especially for Westerners, the jungle is constantly attracting their attention with its variety of colors, sounds, and aromas. The jungle is "alive." The ruins are mostly cleared of the overgrowth. But the process of carving space and architecture from the living jungle never ceases. Nature reclaims its space in all possible places. Tikal was constructed with the understanding of these natural processes. All the structures are massive and heavy. They are made with blocks of solid rock. Only very heavy structures could withstand the vitality of tropical plants. All the built forms are simple. However, what affects one's perception the most is a very unique quality of the relationship existing between natural and the artificial forms. Solid structures as well as open spaces created among them are constantly singled out as discernible symbolic figures and are simultaneously integrated with other elements of artificial and natural order. Tikal may be remembered as an artificial landscape -- a landscape in which forms of constructed mountains and valleys reveal symbolic potency of the natural landscape surrounding them. (See Figure 1.) For a contemporary visitor, the encountered forms truly become found archeological signs, that is, signs which, while heaving all the attributes of an identifiable singular symbolic figure, hide their intended meaning or encourage multiple interpretations.

Steps and stepping play a special role in that environment. On one hand, steps are the closest to the scale of a human body in this scaleless artificial landscape. On the other hand, steps are the very fabric that makes many structures. They mediate between these elemental artificial forms and the topography of the land. Steps create the most unusual experiences as well. After ascending above the jungle, the view from a top of any pyramid, but especially from Temple IV, changes completely the sense of viewing of the reality of Tikal. What seems to be important in that experience is how viewing from above the datum line of the trees differs from

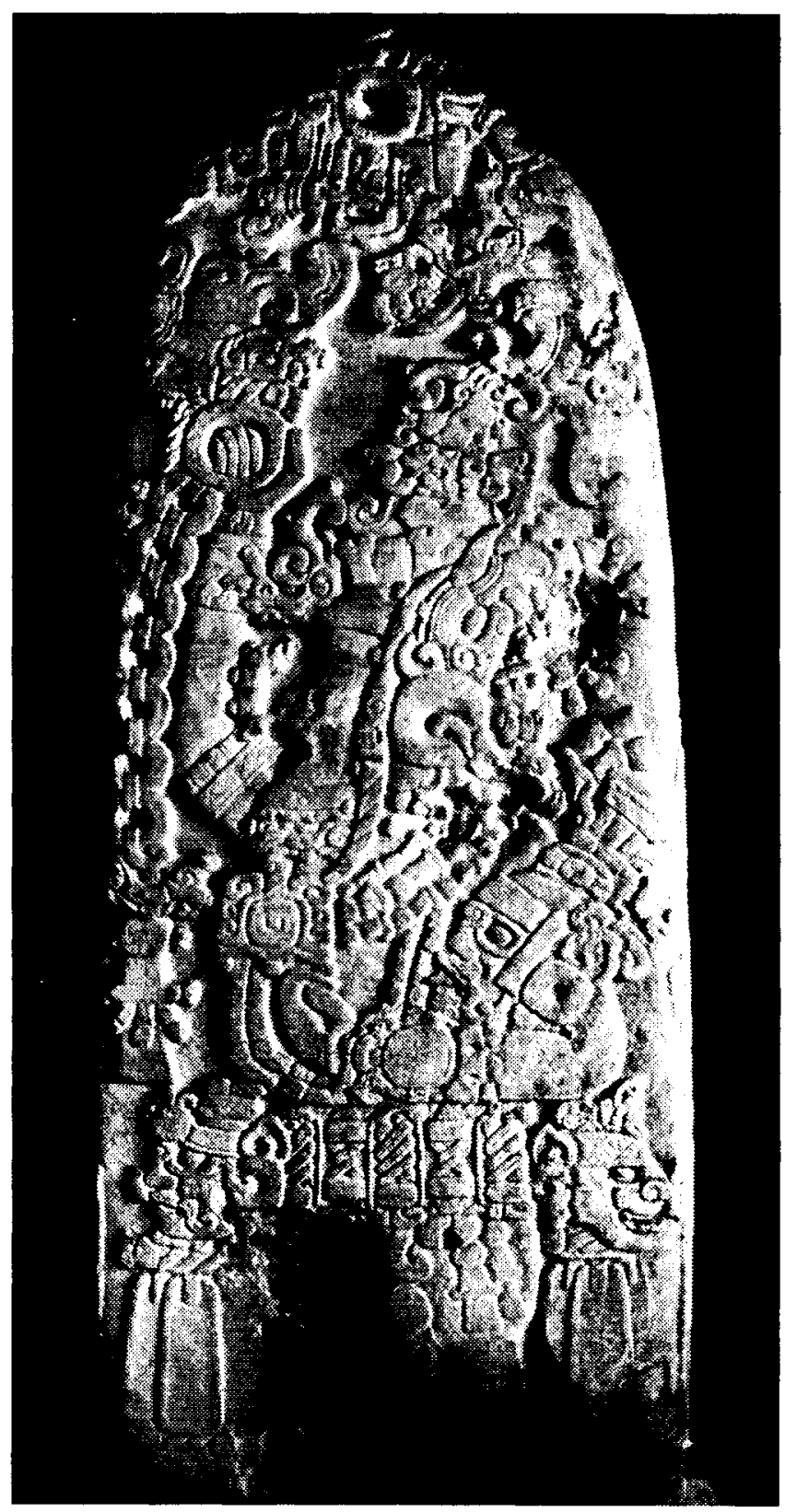

Figure 2. Tikal, stela

any experience one can have on the ground level. Viewed from the ground level, the natural topography of the land is never seen in its entirety. The landscape is always veiled by the foliage of tropical vegetation. Only artificial clearings allow less fragmentary perception. Viewed from the top of the pyramid, Tikal presents itself as a composition of the pyramids on a continues background of the jungle. The pyramids reveal themselves as powerful symbolic singularities. Everything is seen from the outside.

Mayan concern with the complexity of relationships that exist between reality and symbolic interpretations is also apparent in curvings. In Tikal, symbolic depictions, one can find on stelae, create a tapestry of interwoven signs that fill a given area. (See Figure 2.) Representational composition enforces a process of deciphering. There is usually nothing 
obvious about what is singled out as a symbolic figure. At the same time, there are always many clues, forms resembling elements of human body, animals, plants, or tools. A graphic form of Mayan "writing" follows the same pattern. The forms used are simultaneously systematized and pictorial. The written signs are graphically simple. They conform to the rectilinear modularity and they usually tightly and systematically fill the given space. At the same time, each sign preserves its ability to resemble in a pictorial sense.

To summarize the symbolic functioning of Tikal, I wish to assert that the ruins and the symbolic depictions, that can be found in them, create a unique "space of representation." Rather than being a space where previously coded massages may be unequivocally decoded, it is the realm of thought where the thinkable and the meaningful are derived from interconnectedness of natural phenomena and human thought. It is a realm where there is a constant need to read the world for its possibility of embodying a massage. Buildings and symbolic depictions preserve that quality despite their identifiable artificial origin. Instead of perfecting efficiency of communication between a designer (a sender) and a receiver, they are meant to enhance possibility for representational discourse -- meaningful reflection on and more inclusive interpretation of reality based on a dialogue with that reality.

\section{ANTIGUA}

The city of Antigua is profoundly different. It presents itself as a foreign urban fabric imposed upon the land. That fabric consists of architectural elements transplanted from Spain and placed on the grid-like urban pattern of streets. Preservation of these historical elements of a Spanish city makes Antigua a "charming" place. That charm is a nostalgic illusion of a place and time that belong to a distant reality, reality that is somehow familiar to a Westerner. There is no apparent conflict there between the old European urban patterns and the geographical location. Also, there seems to be no conflict there between the needs of contemporary life and the architectural forms of the past.

However, I would like here to look at this cultural phenomenon in the context of The Conquest of America. The encapsulation and transplantation of a distant world reality had its ideological ramifications. The intentionally preserved purity of the Spanish pattern should be seen in the context of the conquest and the colonization of a different culture. Architecture provided the Spaniards with a constant stable point of reference and a set of culturally discernible attributes that made it easier to distinguish between "us" and "them," between the self and the other. Such workings of architecture for the ideological conquest may be uncovered in its symbolic functioning. Lets have, for example, a closer look at the sacral architecture, the churches of Antigua. Almost all of these historical buildings are in ruins or are partly reconstructed after the collapse of their vaulted ceilings. (See Figure 3.) It is not an accident that all the major colonial religious structures did not survive in their original

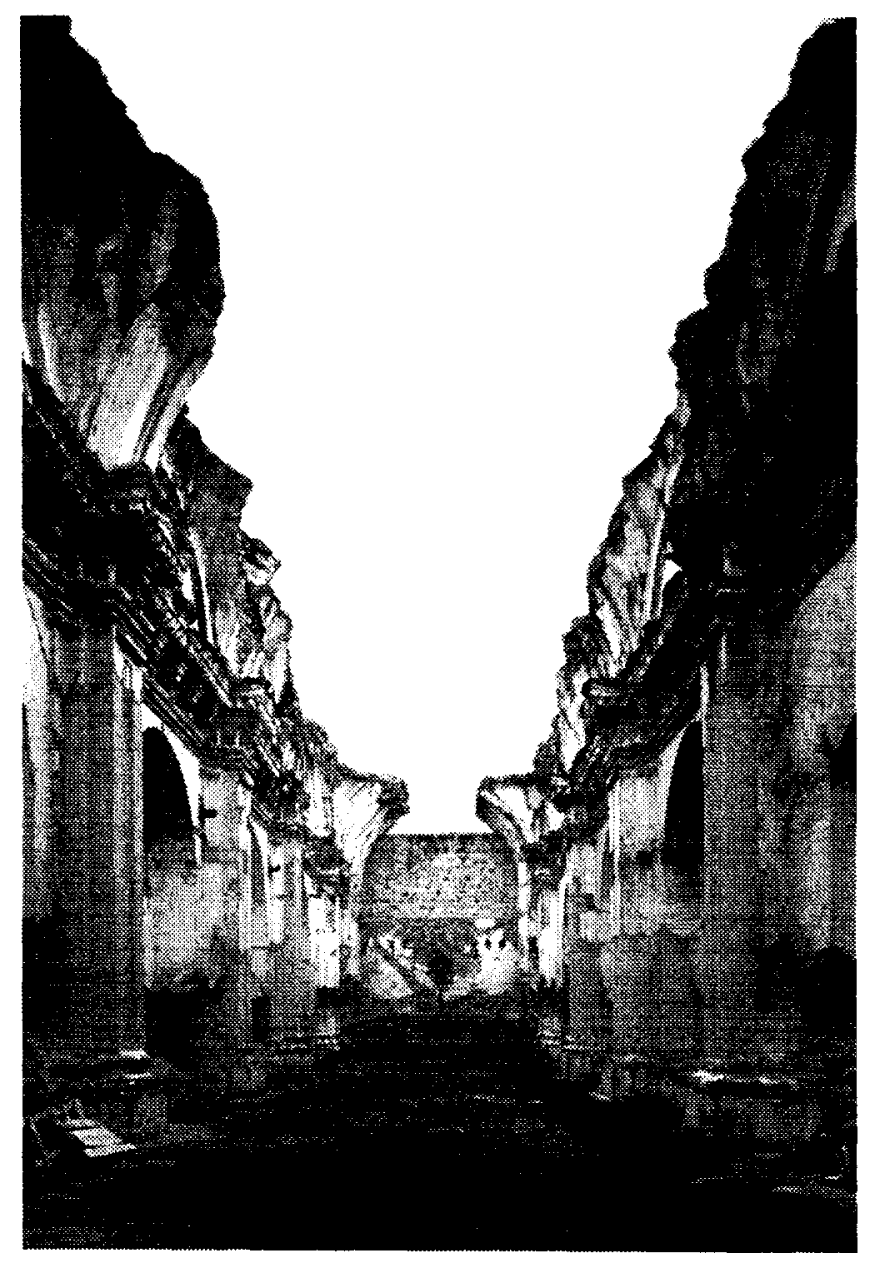

Figure 3. Antigua, ruins of a church

form. Antigua is located close to an active volcano, in a seismicly active area. It seems rather obvious that heavy, thrust-producing, high-elevated, vaulted ceilings would not withstand an earthquake. But, apparently, the physical form of a Catholic temple, including its vaulted ceiling, was seen by its builders as a univocal symbol of their ideology. Consequently, the physical manifestation of such a welldefined symbolic form could not be, or, should never have been compromised by the local idiosyncrasies of geological conditions. ${ }^{6}$ This kind of cultural presumption concerning the constitution of a symbolic sign resides much deeper than the separation between the realms of symbolic and physical realities, the traditional Cartesian duality of spirit and matter. It cannot be explained by a simple lack of geological knowledge either. The character of that presumption may be identified in a different location. Even today, the churches of Antigua contain traces of the constitution of symbolic religious representation that was fundamental for the conquest of the Mayan symbolic reality. All religious sculptures representing sacred figures adhere to the Spanish patterns of the time of colonization. Each sculpture is made to perfectly mimic visual attributes of a human body. Not only a figure must be dressed in physically real and always fresh clothes, 


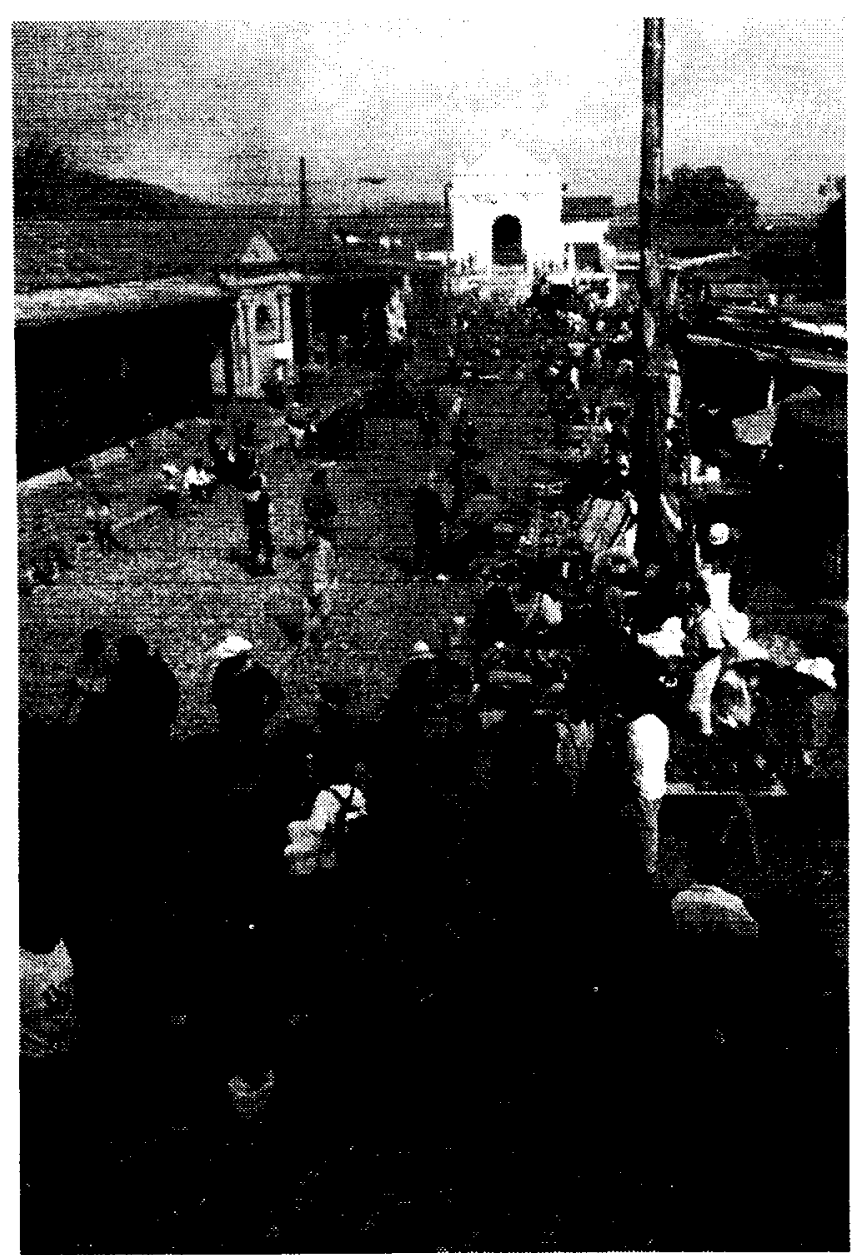

Figure 4. Chichicastenango, view from Iglesia de Santo Tomás toward Capilla del Calvario

but, in many cases, has a wig made of real hair. All the objects that make a particular saint identifiable are made to look like physically real. This level of literalness, based on the separation between a physical appearance and the interpretation of meaning was not a representational concern for the Maya. As I discussed before, Mayan art an architecture derived meaning from a complex interplay between resemblances that included the constructed and the natural, physically present and that which is thinkable. Spanish signification was meant to be unequivocally communicated. The correctness of coding and reading a symbolic massage had to be verifiable in order to be imposed on others. Spanish signs are rationally explicit. They are singled out to be perceived in their physical completeness and rational clarity. The attributes of these symbolic signs are obviously intended to be decoded, they are literal, that is, known and named as physical characteristics. Such signs imply the existence of an identifiable sender of a massage. If that massage is of a symbolic quality, without a doubt, the sender is the authority controlling signification. Such concept of signification belongs to the time of the conquest and colonization. In Spain, the concept of a symbolic sign constitution functioned differently before the discovery of America. ${ }^{7}$ Mayan sym-

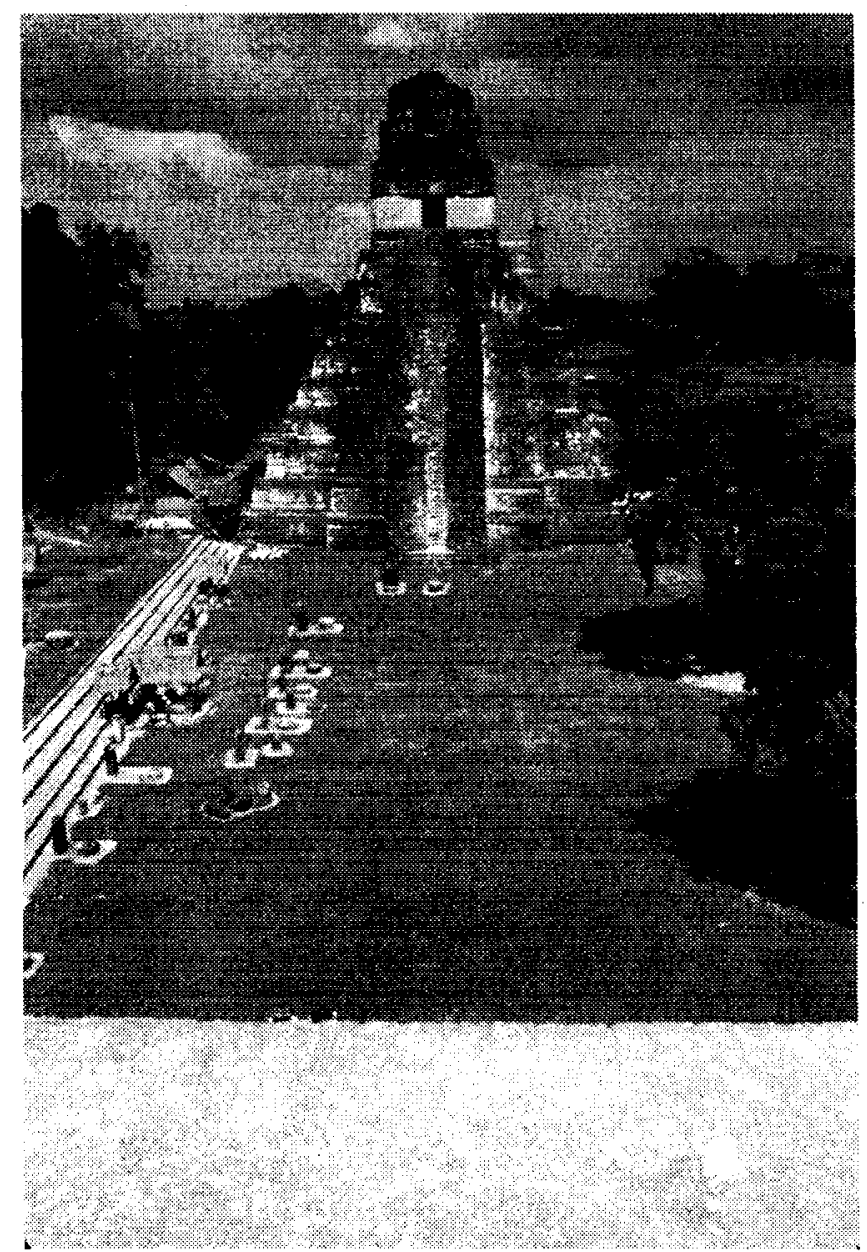

Figure 5. Tikal, view from Temple II toward Temple I

bolic world had to lose the war because their reality was integrated with, thus, was overdetermined by the transcendental rules of the mythical time/universe. These rules combined mythology with physical reality, thus, reconciled what, in the Western understanding, would be inconsistent. The sender of a massage and the authority of Mayan signification were meant to be mythical as a personification of forces existing in the world. Consequently, deciphering, discovering, or "conversing" with such reality was a constant process of defining and locating the "center" of signification. The Spanish symbolic world, on the other hand, was one in which what was real was either controllable or was created as a means of control. The center of that controlling power, securing the correctness of symbolic massage transmission, existed and imposed itself as an ideological and political entity. ${ }^{8}$

\section{CHICHICASTENANGO}

The last Guatemalan city that I would like to discuss is Chichicastenango. Chichicastenango is the name by which this city may be located on Western maps. The native name of the city, Chuguilá Tziguan or Tinamit, preserves the story of its history. It is a small city in the Western mountains of 
Guatemala. Unlike the previous two cities, till today, Chichicastenango is a living center for the indigenous people. In the context of my argument, I would like to present Chichicastenango as a cultural heterotopia. ${ }^{9}$ I would like to uncover there what can be seen as a contemporary outcome of the ideological struggle between the two cultures. Chichicastenango may be seen as a place where urban spaces, architecture, and symbolic practices reveal how Spanish and Mayan world views exist together, not blended, but interwoven.

Chichicastenango is known to the tourists as a place of the biggest market in Guatemala, where the products made by the indigenous people are bought and sold. To the descendants of Maya, Chichicastenango is the place of worship, where Catholic and Mayan rituals are enacted side by side in local churches. On Thursdays and Sundays, the small city is full of Mayans and Western tourists. Local people are always immediately made visible by their colorful clothes, so far not influenced by the Western fashions.

What interests me the most here is the symbolic functioning of architecture and urban space for that local community. First, I would like to study the most urban part of the city, the central market and its two churches. The two churches, the main Iglesia de Santo Tomás and the Capilla del Calvario, organize the space of the square. The churches are east-west oriented on the opposite sides of the southern end of the market. They face each other. This relationship that exists between the two white tall figures of the facades curiously resembles the relationship that exists between the east-west oriented Temple I and Temple II in Tikal. (See Figures.4. and 5.) This similarity might have been considered purely formal if not for the religious activities frequently taking place there. The space created between the two churches is often used as a place for religious processions. The white facades mark the perimeter of that significant space, but most of the religious activities are enacted on the huge stairs leading to, and visually supporting the churches. Noteworthy is that the small-pyramid-like stairs of the Iglesia de Santo Tomás serve as a stage for traditional Mayan prayers, offerings, and incest burning. (See Figure 6.) The main entry to the church, at the top of the steps, is only for chosen indigenous people. Like in Tikal, the steps are slightly overscalled by contemporary standards. They are made of big blocs of local stone. The steps and their cobble-stone surrounding follow the topography. Surprisingly, that piece of stone-covered land reveals its evocative capabilities, the same way the ancient Mayan architecture did. They symbolically mediate between the natural form of the land and the white facade of Spanish architecture. What is more, the colonial architecture is integrated into that play of resemblances. The church, which physically rests on top of the "stone pyramid" instead of dominating it, takes part in that play of associations and similitude. Despite the different proportions and the obvious difference in architectural articulation, the churches evoke in one's memory the small sacred temples located on top of the pyramids in Tikal.

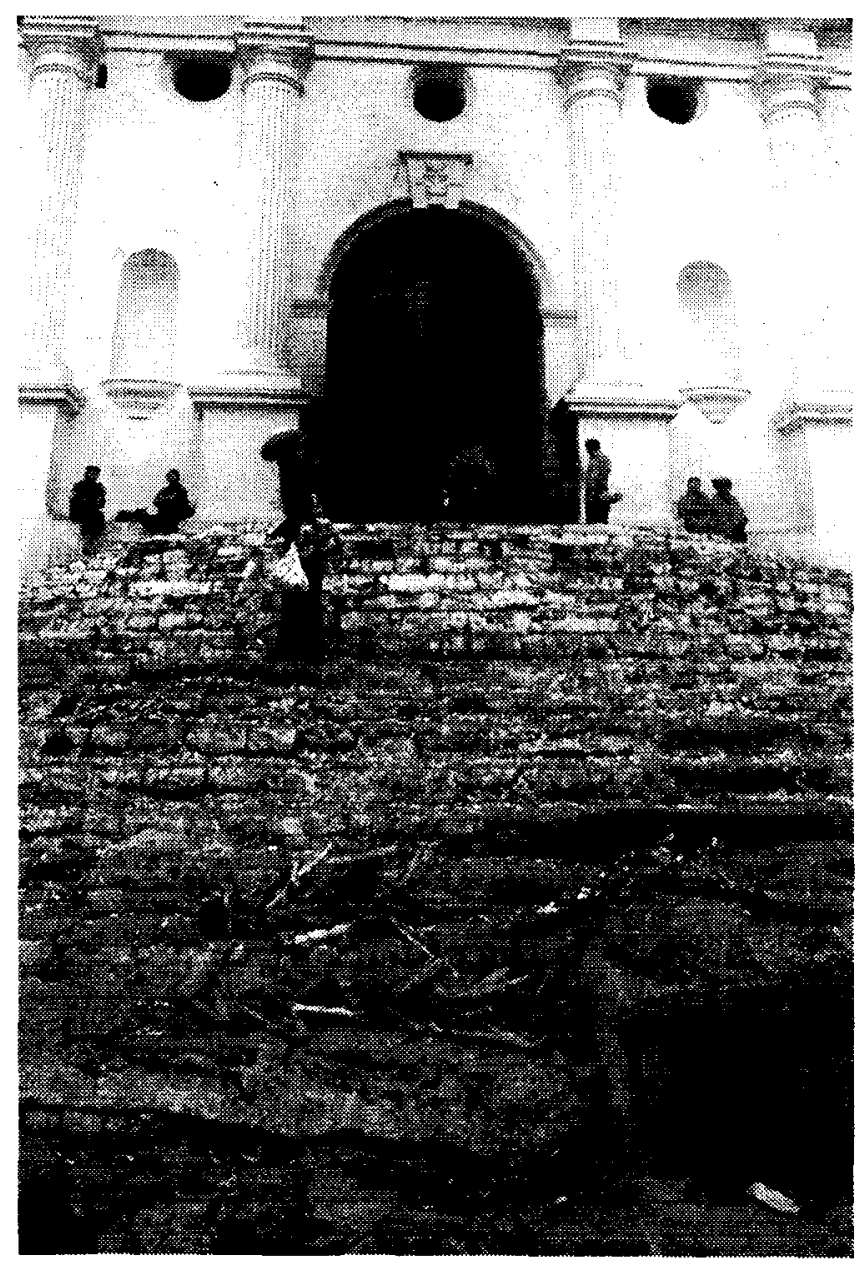

Figure 6. Chichicastenango, Iglesia de Santo Tomás

Maybe, it is their heightened figural quality and the visibility of the dark, centrally-located main entry that makes such a recollection possible. (See Figures 4. and 5.) A space of representation created in that way is the space where thinkable and meaningful subvert the familiar notions of the Western religious symbols. This subtle shifting of what constitutes a Western symbol to infuse it with ideas alien to it may also be found in other places in Chichicastenango. The local cemetery is a place where traditional European forms of tombs are simultaneously preserved and altered. Many of the structures there follow closely, even literally, the Western patterns of building forms and decorating them. However, many of these structures are painted with bright colors. In the traditional Mayan cosmology colors played an important role. Primary colors were associated with the cardinal directions and were orienting the universe. Such unexpected juxtaposition of European forms and Mayan attention to colors produces representational effect unthinkable within traditional Western conventions. In that cemetery, the difference between the Western and the Mayan thinking about the transcendental aspects of life presents itself in the most explicit way. But it is not the conflict that is celebrated. Rather, it is the enrichment of a world view that is celebrated 
by bringing together what is otherwise exclusive. The traditional ability to read and to make sense of reality full of contradictions makes it possible for the Maya descendants to reestablish the harmony of universe even today.

The overall constitution of such space of representation may be seen as an analogue to what Michel de Certeau calls a palimpsest of multiple representations that preserve traditional meaning in form that is illegible to the passerby. ${ }^{10}$ Only by deciphering that palimpsest of symbolic functioning one may understand how complex that cultural heterotopia really is, and how architecture gives a material form to this complex symbolic reality.

\section{CONCLUSION}

In conclusion, I would like to return to Tzvetan Todorov. One of the points he makes is that the conquest of America marks a change in the Western civilization. If that change, as Todorov implies, came with Cortés' understanding that "[t]he conquest of information leads to that of the kingdom," I believe that it is our obligation to test its consequences for our understanding of the function of architecture today. ${ }^{11}$

As I argue in this essay, the conquest of symbolic reality was an effort to make an interpretation of a symbolic meaning univocal, thus, controllable. Ways in which a symbolic sign may be constituted and deciphered were rationally reduced. Symbolic meaning was counted into the category of information, the category of military, scientific, and political tools.

Also, I would like to assert that the conquest of symbolic reality in countries like Guatemala continues. First, the way architecture is known as architectural knowledge, is based on the taxonomy of the winners, the taxonomy of dominating political and cultural centers and their architectural "styles." Heterotopic places, such as Chichicastenango, are almost never included in architecture history books. Usually, they end up being treated as exotic and romanticized tourist attractions, instead of being explored as a place where architecture still preserves its live representational function. Second, the control of symbolic reality became a strategy of the commercial conquest. Urban centers in the countries of Central America are flooded with the commercial iconography of the West. This includes architecture. Consider, for example, architectural statements made by international corporations or by hotels. However, the functioning of visual advertisements is the most explicit. These images are hyperreal because of their enhanced photo-realism. They are commercially literal. Their univocal massages are made known in a persuasive and aggressive way. This commercial invasion continues an effort to erase the traces of the old value systems, that is the traditional symbolic reality that will always remain to be "the other" for the West.

\section{NOTES}

1 Tzvetan Todorov, The Conquest of America (New York, N.Y.: Harper \& Row Publishers, 1987)

2 Todorov, p. 69. and p. 97.

3 Todorov, p. 64.

${ }^{4}$ Michel Foucault, The Order of Things (New York, N.Y.: Random House, 1973), pp. 63-67.

5 These processes have been studied by Foucault in his books analyzing the emergence of epistemological and institutional formations of medicine and penal system; see, for example, Discipline and Punish or The Birth of Clinic.

${ }^{6}$ There are many examples of such symbolic intolerance in The Conquest of America. For example, Montezuma, the king of Aztecs, offered an ideological compromise. He proposed to include Christian God into the pantheon of Aztec divinities. Such concept was unacceptable for the Spaniards and was rejected. See Todorov, pp. 105-106.

7 This radical change may be seen, for example, in the exhibition of religious sculpture presented in the Museo Marés in Barcelona. In The Conquest of America, Todorov asserts that, despite a short period of time separating them, even the comparison between Columbus' and Cortés' actions reveal such a shift in the understanding and the manipulation of symbolic reality. Columbus "found" America because he believed in prophecies. (See Todorov, pp. 22, 23.) Cortés' primary concern was the military and political conquest based on the control of information.

${ }^{8}$ Diana I. Agrest suggests that "[the] turning point in the representation of the [European] city coincides with the formation of the capitol city." Antigua was such a new urban tool of persuasion. Diana 1. Agrest, "City as Place of Representation" in Architecture from Without (Cambridge, Mass.: The MIT Press, 1991) p. 112.

${ }^{9}$ Heterotopia may be defined here a place where exclusive ideological influences and contradictory concepts of epistemology are coexistent; heterotopias exist as the other to all the places that are considered to be "normal" in a given culture; see Michel Foucault, "Of the Other Spaces," Diacritics (Spring 1986): 22-27.

${ }^{10}$ Michel de Certeau, "The Politics of Silence: The Long March of the Indians" in Heterologies: Discourse on the Other (Minneapolis, MN: University of Minnesota Press 1989) p. 229.

11 Todorov, p. 104. 